\title{
SUSCETIBILIDADE À DESERTIFICAÇÃO DAS TERRAS SECAS DE GILBUÉS (ESTADO DO PIAUÍ) E CABROBÓ (ESTADO DO PERNAMBUCO), NORDESTE DO BRASIL
}

\author{
DESERTIFICATION SUSCEPTIBILITY OF GILBUÉS \\ (PIAUÍ STATE) AND CABROBÓ (PERNAMBUCO STATE) \\ DRYLANDS, IN NORTHEASTERN BRAZIL
}

\author{
Laryssa Sheydder de O. Lopes ${ }^{1}$ \\ Universidade Federal de Pernambuco, Brasil \\ Rafael Celestino Soares ${ }^{2}$ \\ Universidade Federal do Ceará., Brasil
}

\begin{abstract}
RESUMO
Desertificação é um processo de fragilidade dos ecossistemas de terras secas em geral que, em decorrência da pressão excessiva exercida pelas populações humanas, perde sua produtividade e capacidade de regenerar-se. $\mathrm{O}$ objetivo deste trabalho foi discutir a suscetibilidade à desertificação de duas áreas-piloto no Nordeste do Brasil: Gilbués (Piauí) e Cabrobó (Pernambuco). Estas áreas possuem características geológicas, de solo, clima e vegetação diferenciadas, no entanto, as atividades humanas possuem pontos em comum, tais como a agricultura, o desmatamento e a pecuária. A metodologia utilizada foi o levantamento bibliográfico e pesquisa de campo para coleta de dados e registros fotográficos. As consequências da desertificação resultam no empobrecimento
\end{abstract}

1 Doutoranda em Geografia (Universidade Federal de Pernambuco - UFPE). Av. Professor Morais Rego, 1235 - Cidade Universitária, Recife - PE, 50670-901. E-mail: sheydder@yahoo.com.br.

2 Doutorando em Geologia (Universidade Federal do Ceará- UFC). Avenida da Universidade, 2853 - Benfica, Fortaleza - CE, 60020-181. E-mail: rafaelcsoares@yahoo.com.br.

Fecha de recepción: 26 de setiembre del 2015

Fecha de aceptación: 09 de diciembre del 2015 
Laryssa Sheydder de O. Lopes, Rafael Celestino Soares. Desertification susceptibility of Gilbués (Piauí State) and Cabrobó (Pernambuco State) drylands, in northeastern Brazil.

DOI: http://dx.doi.org/10.15359/rgac.1-56.13

da população local e declínio da qualidade ambiental, como também em processos migratórios intraregionais, perda de biodiversidade e de território.

Palavras-chave: Degradação ambiental; Indicadores de desertificação; Núcleos de desertificação; Atividade antrópica

\begin{abstract}
Desertification is a process of weakness of the drylands ecosystems in general that, due to the excessive pressure from human populations, loses its productivity and capacity to regenerate itself. The objective of this study was to discuss the susceptibility to desertification in two pilot areas in Northeastern Brazil: Gilbués (Piaú State) and Cabrobó (Pernambuco State). These areas have differentiated characteristics of geology, soil, climate and vegetation. However, human activities have points in common, such as agriculture, deforestation and livestock. The methodology was the literature review and field research to collect data and photographic records. The consequences of desertification result in the local population impoverishment and loss of environmental quality, as well as in regional migration processes, loss of biodiversity and territory.
\end{abstract}

Keywords: Environmental Degradation; Desertification Indicators; Desertification Centers; Anthropic Activity.

\title{
Introdução
}

Desertificação é um processo de fragilidade dos ecossistemas de terras secas em geral, que, em decorrência da pressão excessiva exercida pelas populações humanas, ou às vezes pela fauna autóctone, perdem sua produtividade e capacidade de regenerar-se (Matallo JR, 2001).

De acordo com Melo et al (2008) as causas da desertificação muitas vezes são confundidas com as consequências e não chega à um consenso uma vez que não se pode deixar de considerar as características naturais e nem a dinâmica de ocupação do território, ambos são condicionantes da vulnerabilidade socioambiental de cada área.

Combater a desertificação implica em desenvolver ações voltadas ao controle e prevenção deste processo e, quando possível, recuperar as áreas degradadas, assim como é importante também suprimir as causas que provocam estas consequências.

O objetivo do combate à desertificação, por sua vez, está restrito à prevenção e recuperação de terras degradadas, ou seja, dos sistemas bioprodutivos que compreendem os processos ecológicos do sistema não havendo uma preocupação direta com a dimensão econômica e social, o que diverge das considerações que justificam a Convenção das Nações Unidas para Conservação da Natureza (UNCCD) quando afirma que os 
Laryssa Sheydder de O. Lopes, Rafael Celestino Soares. Suscetibilidade à desertificação das terras secas de Gilbués (Estado do Piauí) e Cabrobó (Estado do Pernambuco), nordeste do Brasil.

DOI: http://dx.doi.org/10.15359/rgac.1-56.13

seres humanos e as ameaças estão no centro das preocupações do combate à desertificação e mitigação dos efeitos da seca (Sampaio et al, 2005).

\section{Metodologia}

A metodologia deste trabalho constou do levantamento bibliográfico, em livros, periódicos e sites dos órgãos públicos; e pesquisa de campo nas duas áreas de estudo: Gilbués, no estado do Piauí e Cabrobó, no estado de Pernambuco, Brasil. Durante a pesquisa de campo foram coletados dados a partir de entrevistas e realizado registro fotográfico.

\section{Desertificação: debate conceitual}

Durante a década de 1930, alguns estados norte-americanos sofreram com a forte seca dos anos 1929 e 1930, no entanto, os estudos acerca da desertificação ganharam visibilidade mundial durante a seca de 19681973, na região de Sahel, na África. A partir deste momento, iniciaram-se as discussões, em nível mundial, sobre a desertificação, com a realização da Conferência das Nações Unidas para o Meio Ambiente, em Estocolmo, no ano de 1972, que resultou na elaboração do relatório Estudo do Impacto Humano no Clima (SMIC) (Silva; Silva, 2015).

O SMIC serviu de base para a realização do Programa das Nações Unidas para o Meio Ambiente (PNUMA), em 1977, da Conferência das Nações Unidas Sobre Desertificação em Nairóbi, África, que teve a finalidade de divulgar a problemática como um problema mundial (Silva; Silva, 2015).

A definição do conceito de desertificação apresenta algumas controvérsias. De acordo com o PNUMA, desertificação consiste na degradação de terras áridas, semiáridas e subáridas, resultante, principalmente, dos impactos das ações humanas (Suertegaray, 2000). Em contrapartida, a (UNCCD), definiu desertificação como a degradação de terras áridas, semiáridas e subúmidas secas, resultantes de vários fatores, dentre eles, as variações climáticas e as atividades humanas (Brasil, 1997).

Desertificação é um processo de fragilidade dos ecossistemas de terras secas em geral, que, em decorrência da pressão excessiva exercida pelas populações humanas, ou às vezes pela fauna autóctone, perdem sua produtividade e capacidade de regenerar-se (Vasconcelos Sobrinho, 1971). Nimmer (1988 apud Suertegaray, 2000) considera a desertificação como a crescente degradação ambiental expressa pelo ressecamento e perda de 
Laryssa Sheydder de O. Lopes, Rafael Celestino Soares. Desertification susceptibility of Gilbués (Piauí State) and Cabrobó (Pernambuco State) drylands, in northeastern Brazil.

DOI: http://dx.doi.org/10.15359/rgac.1-56.13

capacidade de produção dos solos, que pode ser em decorrência da mudança do clima regional e/ou do uso inadequado dos solos pelo homem.

O conceito é complexo uma vez que o termo "degradação de terras" compreende também os solos, vegetação, recursos hídricos e redução da qualidade de vida da população. Dessa forma, esses componentes dizem respeito a quatro grandes áreas do conhecimento (físico, biológico, hidrológico e socioeconômico) e cada um trabalha a temática da desertificação de acordo com seus interesses e objetos de estudo (HARE, 1992).

O conceito definido pela UNCCD também restringe a desertificação a uma parte do Nordeste do Brasil e ao norte do estado de Minas Gerais. Em outras áreas pode haver degradação das terras semelhantes, mas não podem ser denominadas de desertificação, não se enquadrando no conceito da UNCCD. Quando citado "vários fatores, incluindo as variações climáticas e as atividades humanas", o termo "vários fatores" deixa uma margem a que, qualquer degradação de terra, seja qual for a causa, seja considerada desertificação; "as variações climáticas" é indefinido como fenômeno variável por natureza, sem esclarecer sua abrangência espacial e temporal; e "as atividades humanas", sem qualitativos, é tao abrangente que pode incluir as ações pretéritas e do presente (Sampaio et al, 2005).

O que se pode observar é a falta de uma metodologia unificada para avaliar os processos de desertificação, problema ressaltado por Matallo Jr (2001, p.21) quando afirma que "as atuais metodologias de estudo da desertificação não se configuram como método no sentido clássico, mas como um aglomerado de conhecimentos de diferentes áreas que se deseja colocar a serviço da compreensão do problema".

Durante a Conferência das Nações Unidas sobre Desertificação, em 1977, foram definidos os Indicadores de Desertificação (Quadro 1): 
Laryssa Sheydder de O. Lopes, Rafael Celestino Soares. Suscetibilidade à desertificação das terras secas de Gilbués (Estado do Piauí) e Cabrobó (Estado do Pernambuco), nordeste do Brasil.

DOI: http://dx.doi.org/10.15359/rgac.1-56.13

Quadro 1: Indicadores de Desertificação segundo a Conferência das Nações Unidas sobre Desertificação (UNCCD)

\begin{tabular}{|l|l|}
\hline $\begin{array}{l}\text { Indicadores } \\
\text { Climáticos }\end{array}$ & radiação solar; temperatura; velocidade do vento; precipitação \\
\hline $\begin{array}{l}\text { Indicadores } \\
\text { Hidrológicos }\end{array}$ & $\begin{array}{l}\text { sólidos dissolvidos em água; mudança de fluxos de água e dos depósitos } \\
\text { sedimentares no canal de escoamento; profundidade do lençol freático; } \\
\text { qualidade da água; descarga dos rios; umidade do solo; fluxo subsuperficial; } \\
\text { água de escoamento e produção de sedimentos. }\end{array}$ \\
\hline $\begin{array}{l}\text { Indicadores } \\
\text { Pedológicos }\end{array}$ & $\begin{array}{l}\text { profundidade do solo; capacidade de acumulação de água; composição } \\
\text { dos horizontes; estado da superfície; teor de matéria orgânica; albedo; } \\
\text { grau de salinização e alcanilização; teor de pedregosidade; encrostamento; } \\
\text { fendilhamento; compactação e permeabilidade da crosta. }\end{array}$ \\
\hline $\begin{array}{l}\text { Indicadores } \\
\text { Biológicos }\end{array}$ & $\begin{array}{l}\text { grau de cobertura e altura da vegetação; biomassa aérea e subterrânea; } \\
\text { rendimentos; distribuição e frequência de espécies; organização e } \\
\text { profundidade das raízes; queda e organização de folhas; produção primária; } \\
\text { produção de pastoreio; composição de espécies; atraso de germinação; }\end{array}$ \\
\hline $\begin{array}{l}\text { Indicadores } \\
\text { Sociológicos }\end{array}$ & distribuição espacial de implantações humanas. \\
\hline
\end{tabular}

Fonte: Adaptado de SANTOS, 2011.

Diante da complexidade dos Indicadores de Desertificação, torna-se necessário uma abordagem interdisciplinar desta problemática socioambiental. É estratégico utilizar um sistema de indicadores como uma ferramenta que possibilita identificar sistemas ambientais e comunidades vulneráveis à desertificação, assim como o desenvolvimento de ações adequadas para avaliar e monitorar as políticas públicas implementadas (Santos, 2011).

A fragilidade ambiental, social ou econômica, ou seja, a baixa capacidade de reagir às condições adversas, tem sido usada como medida da suscetibilidade. Essa medida é importante na determinação do risco, na estimativa da progressão de desertificação já em curso e na avaliação de ações preventivas.

Combater a desertificação implica em desenvolver ações voltadas ao controle e prevenção deste processo e, quando possível, recuperar as áreas degradadas, assim como é importante também suprimir as causas que provocam estas consequências.

O objetivo do combate à desertificação, por sua vez, está restrito à prevenção e recuperação de terras degradadas, ou seja, dos sistemas bioprodutivos que compreendem os processos ecológicos do sistema não havendo 
Laryssa Sheydder de O. Lopes, Rafael Celestino Soares. Desertification susceptibility of Gilbués (Piauí State) and Cabrobó (Pernambuco State) drylands, in northeastern Brazil.

DOI: http://dx.doi.org/10.15359/rgac.1-56.13

uma preocupação direta com a dimensão econômica e social, o que diverge das considerações que justificam a UNCCD quando afirma que os seres humanos e as ameaças estão no centro das preocupações do combate à desertificação e mitigação dos efeitos da seca (Sampaio et al, 2005).

De acordo com Melo et al (2008) as causas da desertificação muitas vezes são confundidas com as consequências e não chega à um consenso uma vez que não se pode deixar de considerar as características naturais e nem a dinâmica de ocupação do território, ambos são condicionantes da vulnerabilidade socioambiental de cada área.

Ab’Saber (2010) qualifica a desertificação como antrópica, afirmando que não só as áreas semiáridas, mas também as faixas de transição entre regiões úmidas e as regiões secas do Nordeste, sofrem mais processo de degradação ambiental do que a própria área nuclear da caatinga, a exemplo das duas áreas pesquisadas neste trabalho.

\section{Núcleos de Desertificação}

Em 1979, uma equipe de ecologistas, agrometeorologistas, edafólogos, entomologistas, sociólogos e matemáticos identificaram quatro núcleos de desertificação no Nordeste brasileiro e estudaram os processos de degradação ambiental destas áreas.

Por núcleos de desertificação entendem-se as "unidades mínimas" a partir das quais os estudos devem ser conduzidos, devido à impossibilidade da abordagem de grandes áreas como a de um estado (Rodrigues, 1986). Convém ressaltar que o termo "núcleos de desertificação" foi adotado pelo pernambucano João Vasconcelos Sobrinho, considerado o pioneiro nos estudos da temática, a partir de sua monografia, intitulada "Núcleos de Desertificação no Polígono das Secas”, publicada em 1971 (Hare et al, 1992).

A formulação da categoria "núcleos de desertificação" foi uma das estratégias usadas por Vasconcelos Sobrinho com vistas a permitir melhor aproximação com o fenômeno, ou seja, para permitir uma abordagem a nível local. Na contextualização os núcleos, que aparecem inicialmente com a nomenclatura "áreas-piloto", o autor afirma que a impossibilidade de um estudo abrangente de uma área por demais vasta, como um Estado ou de todo o polígono das secas, nos impõe a escolha de áreas bem específicas, bem representativas, passíveis de serem estudadas como área-piloto (Perez-Marín et al, 2012, p. 92). 
De acordo com Vieira et al (2015) no Brasil, as áreas desertificadas mais críticas estão localizadas no semiárido nordestino. O clima, o tipo de solo, a geologia, a vegetação, os fatores socioeconômicos e a gestão destas áreas são os aspectos importantes a serem considerados neste processo. Um fator agravante é a concentração populacional nestas áreas. De acordo com o IBGE (2010) o semiárido é a região de terra seca com a maior concentração populacional, cerca de 53 milhões de habitantes, aproximadamente $34 \mathrm{hab} / \mathrm{km}^{2}$.

Foram identificados quatro núcleos no Nordeste brasileiro: Gilbués, no Piauí; Cabrobó, em Pernambuco; Irauçuba, no Ceará; e Seridó, no Rio Grande do Norte. Os dois primeiros núcleos citados são as áreas de estudo desta pesquisa (figura 1).

Figura 1. Mapa de localização dos Núcleos de Desertificação no Nordeste Brasileiro

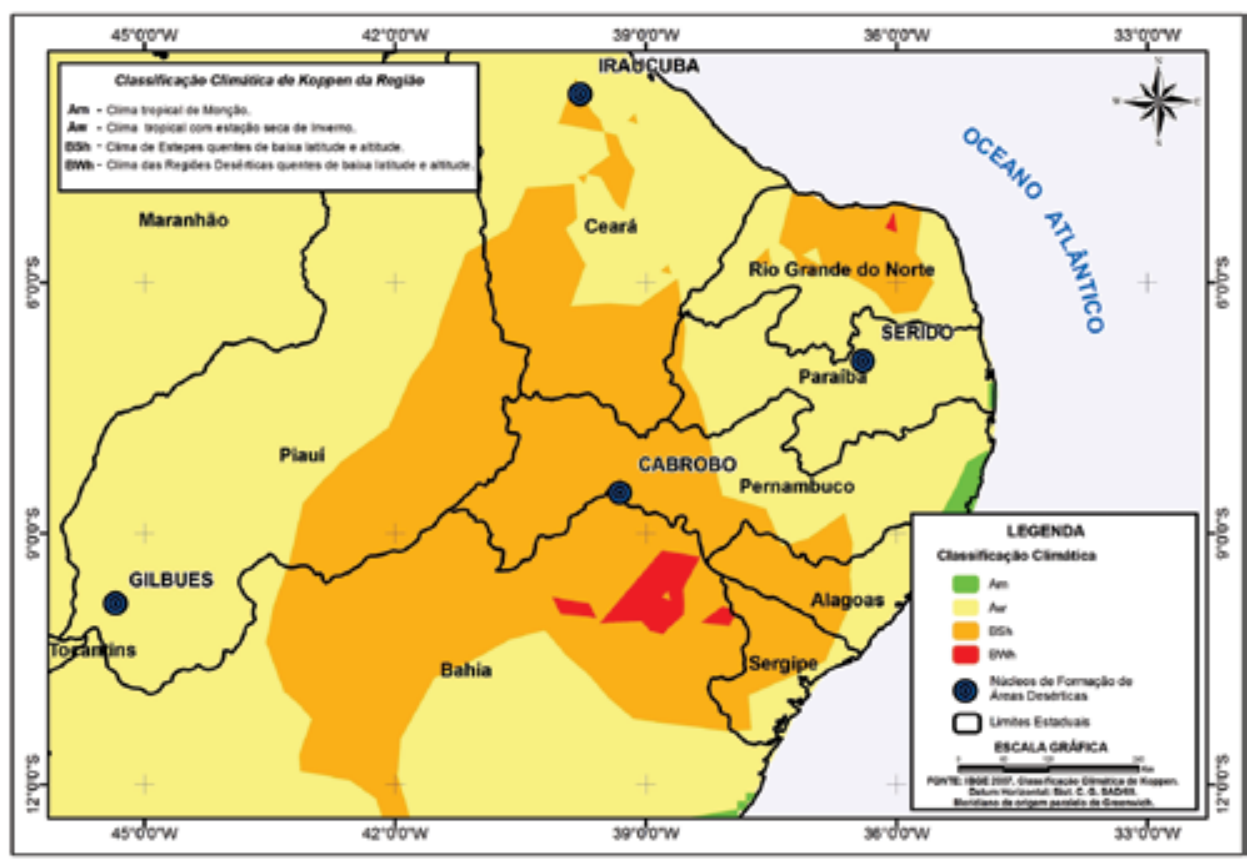

Fonte: LOPES, 2014. 
Laryssa Sheydder de O. Lopes, Rafael Celestino Soares. Desertification susceptibility of Gilbués (Piauí State) and Cabrobó (Pernambuco State) drylands, in northeastern Brazil.

DOI: http://dx.doi.org/10.15359/rgac.1-56.13

O Núcleo de Gilbués está localizado no extremo sul do estado do Piauí e abrange os municípios de Gilbués e Monte Alegre do Piauí. A área afetada é de cerca de $6.000 \mathrm{~km}^{2}$, atingindo uma população de 20.000 habitantes. Gilbués apresenta características bastante diferentes dos outros núcleos de desertificação do Nordeste no tocante aos aspectos ambientais. (Perez-Marín et al, 2012). De acordo com o IBGE (2014), o Índice de Desenvolvimento Humano (IDH) de Gilbués é de 0,548.

O Núcleo de Cabrobó está localizado no sul do estado de Pernambuco e abrange os municípios de Cabrobó, Belém do São Francisco, Carnaubeira da Penha, Itacuruba e Floresta. Compreende uma área de cerca de $5.000 \mathrm{~km}^{2}$ e afeta uma população em torno de 24.000 habitantes (Perez-Marín et al, 2012). De acordo com o IBGE (2014), o Índice de Desenvolvimento Humano de Cabrobó é de 0,623.

Em Gilbués, o fator mais marcante na paisagem, são as áreas com acentuado processo de erosão, com ocorrência frequente de profundas voçorocas e grandes depósitos de sedimentos revolvidos (figura 2). As voçorocas avançam sobre propriedades rurais, estradas e no núcleo urbano do município.

Figura 2: Voçoroca no município de Gilbués, Piauí, Brasil.

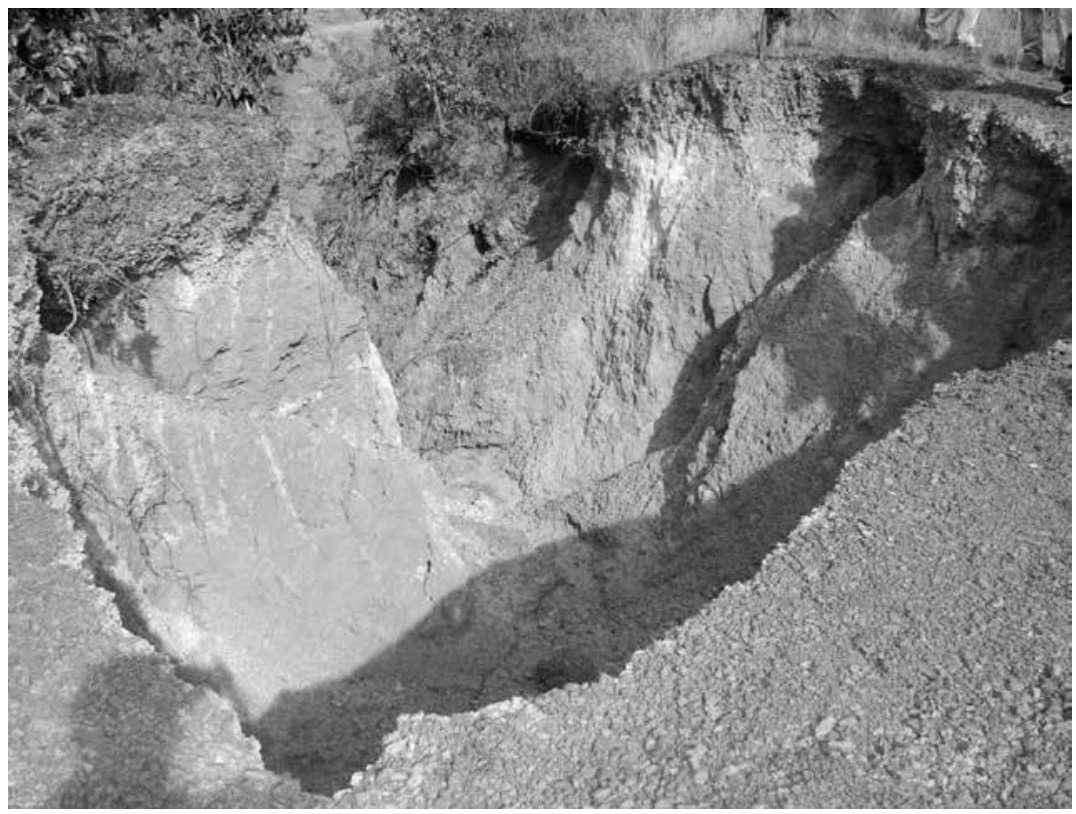

Foto: Lopes, 2007. 
De acordo com Sales (2003), as causas deste processo de degradação do solo estão ligadas principalmente à geologia local. A região está sobre terrenos do paleozoico da bacia sedimentar do Parnaíba e do mesozoico da bacia do São Francisco. A litologia apresenta-se bastante vulnerável à erosão uma vez que é composta por siltitos, arenitos e conglomerados das Formações Poti, Piauí, Aerado e Urucuia.

O relevo corresponde à superfícies tabulares de estrutura horizontal (chapadões) e feições em rampas intensamente dissecadas por processo de escoamento concentrado. A erosão laminar e da remoção dos horizontes A e B dos solos ocorre devido aos efeitos da erosão eólica, no período seco que vai de maio a outubro, e da hídrica, devido ao elevado e concentrado índice pluviométrico, em torno de $1.200 \mathrm{~mm}$ anuais de dezembro a março. A grande quantidade de sedimentos transportados ocasiona o assoreamento de rios, lagoas e barragens (Pfaltzgraff, 2010).

A acentuada morfogênese natural da área (consequência de suas características litológicas, climáticas, pedológicas e vegetais), associada às intensas pressões de caráter antrópico, configura o quadro de desertificação que compromete fortemente o meio ambiente e a economia regional (Pfaltzgraff, 2010, p. 83).

Em Cabrobó a degradação do solo mais visível na paisagem está relacionada ao processo de salinização (figura 3). Este processo de acúmulo de sais é comum em áreas áridas e semiáridas, ambientes em que as taxas de evaporação são maiores que as taxas de precipitação, que o caracteriza como um processo natural, no entanto, a agricultura irrigada, muito utilizada na região, acelera este processo, na medida em que a água da superfície evapora, favorecendo o acúmulo de sais na camada superficial do solo. 
Laryssa Sheydder de O. Lopes, Rafael Celestino Soares. Desertification susceptibility of Gilbués (Piauí State) and Cabrobó (Pernambuco State) drylands, in northeastern Brazil.

DOI: http://dx.doi.org/10.15359/rgac.1-56.13

Figura 3: Camada espessa de sais na superfície do solo na Ilha de Assunção, em Cabrobó, Pernambuco, Brasil.

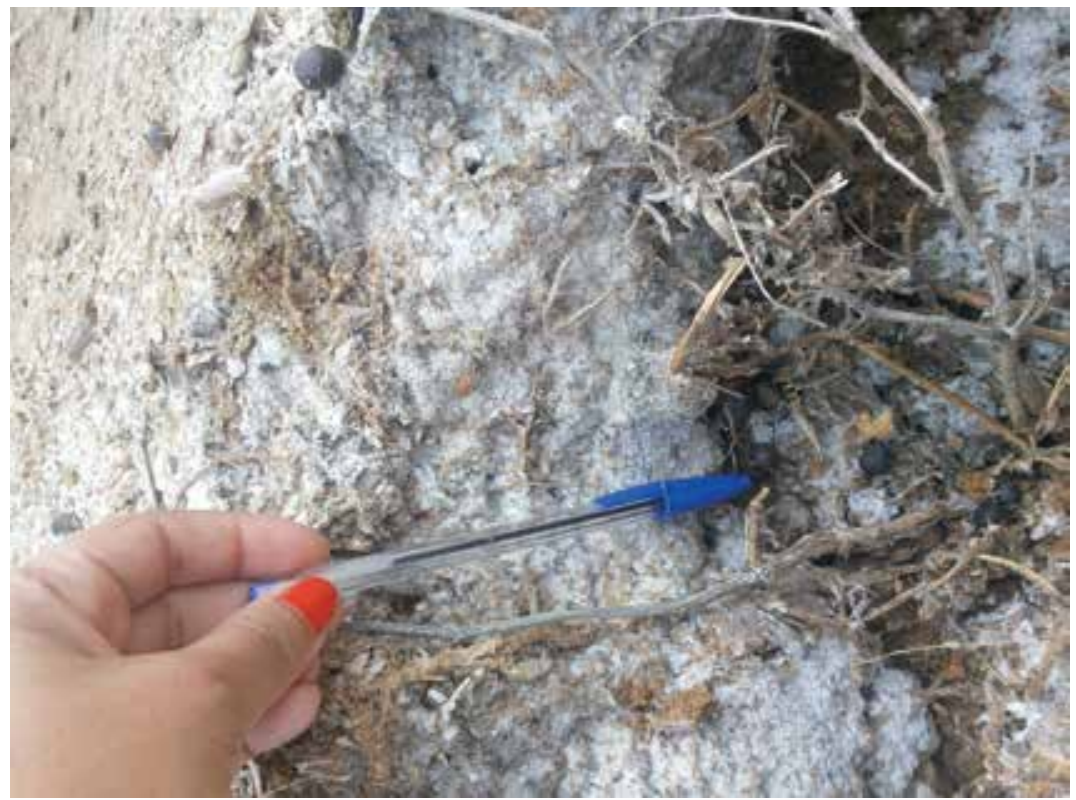

Foto: Lopes, 2014.

Devido à aridez e os solos rasos do Escudo Cristalino, a região de Cabrobó tem uma capacidade de suporte limitada. As feições planas de relevo da Depressão Sertaneja, com declives em torno de 3\%, deixam vulneráveis à salinização as áreas mais rebaixadas, onde a drenagem é limitada. A erosão também é favorecida devido à vulnerabilidade dos solos do tipo Argissolos, Planossolos, Luvissolos e Neossolos encontrados na região.

Estes solos são mal drenados e com permeabilidade baixa, fator responsável por deixar o lençol freático suspenso durante o período chuvoso, aumentando o teor de sais. Além disso, a argila expansiva presente no horizonte B e a grande quantidade de seixos, geralmente dão origem a cascalheiras em áreas que sofrem desmatamento. A argila floculada em água é facilmente carreada em solo desprotegido restando apenas o material pedregoso (Soares, 2011).

As condições climáticas das duas áreas pesquisadas também apresentam dinâmicas diferentes. Situado na região de clima semiárido, o município de Cabrobó tem como característica pluviométrica a irregularidade 
Laryssa Sheydder de O. Lopes, Rafael Celestino Soares. Suscetibilidade à desertificação das terras secas de Gilbués (Estado do Piauí) e Cabrobó (Estado do Pernambuco), nordeste do Brasil.

DOI: http://dx.doi.org/10.15359/rgac.1-56.13

espaço-temporal, ou seja, as chuvas ocorrem de forma concentrada e em curto período de tempo, assim como em Gilbués, situado em clima subúmido. Enquanto em Cabrobó, o índice pluviométrico é em torno de $500 \mathrm{~mm}$ anuais, em Gilbués, as chuvas são torrenciais e o índice pluviométrico é de $1.200 \mathrm{~mm}$ anuais. Além da má distribuição anual das chuvas, há uma alta variabilidade interanual, com anos chuvosos intercalados com longos anos de seca.

As elevadas temperaturas durante todo o ano influenciam a evapotranspiração potencial e, quando associadas aos índices de precipitação gera um índice de aridez. Quando a razão estiver entre 0,05 e 0,20, o clima é considerado árido; entre 0,21 e 0,50, o clima é considerado semiárido e, quando for entre 0,51 e 0,65 , o clima é considerado subúmido seco.

Cabrobó apresenta o índice de aridez de 0,31 , enquadrando-se, portanto no clima semiárido, assim como na definição das áreas de desertificação da UNCCD. A controvérsia está em relação à Gilbués, onde o índice de aridez está entre 0,71 a 0,96 , não se enquadrando em nenhuma das categorias de clima definidas pela UNCCD como sendo suscetíveis à desertificação conforme os trabalhos de Aquino et al (2006).

As atividades humanas contribuem consideravelmente para a degradação ambiental nos dois núcleos. De acordo com Vieira et al (2015) a exploração excessiva dos recursos naturais, em regiões extremamente vulneráveis, podem acelerar o processo de degradação e desertificação da terra, afetando as funções dos ecossistemas e prejudicando a produtividade, a biodiversidade e a heterogeneidade da paisagem, representando uma grande ameaça para o meio ambiente e o bem-estar humano.

O processo de ocupação do estado do Piauí deu-se a partir da instalação de fazendas de gado no século XVII, com a prática da pecuária extensiva (Sales, 2013). As terras secas do nordeste brasileiro não suportam uma grande densidade de animais uma vez que, durante o período de estiagem, há uma redução da pastagem, fazendo os produtores adotarem a técnica da criação extensiva. Em Cabrobó a criação dos rebanhos também ocorre, historicamente, de forma extensiva.

O pisoteio do gado, no entanto, não é o fator de maior impacto da degradação dos solos, mas o processo de queima e retirada da cobertura vegetal que, consequentemente, deixa o solo mais exposto à erosão. Este quadro não sofreu alterações significativas ao longo dos anos nas áreas 
Laryssa Sheydder de O. Lopes, Rafael Celestino Soares. Desertification susceptibility of Gilbués (Piauí State) and Cabrobó (Pernambuco State) drylands, in northeastern Brazil.

DOI: http://dx.doi.org/10.15359/rgac.1-56.13

pesquisadas, havendo apenas o incremento de outras atividades, como a já declinada exploração de diamantes e a expansão da fronteira agrícola, no caso de Gilbués.

Segundo dados do IBGE (2014), em Gilbués, no ano de 2010, a extração de lenha foi aproximadamente $24.000 \mathrm{~m}^{3} \mathrm{e}$ a pecuária não é tão representativa com um rebanho bovino de cerca de 18.000 cabeças e caprino de cerca de 2.000 cabeças. Este quadro se agrava em Cabrobó, onde a produção de carvão vegetal foi de 34 toneladas e o rebanho caprino tem maior representatividade, com quase 29.000 cabeças. Desta forma, considerando que a área de Cabrobó é de $1.657 \mathrm{~km}^{2}$, aproximadamente metade da área de Gilbués, que é de $3.494 \mathrm{~km}^{2}$, a densidade, tanto de rebanho quando de produção de lenha é maior em Cabrobó.

os caprinos têm a capacidade de descobrir o alimento escondido escavando no solo os tubérculos oem a casca, impedindo sua regeneração após as queimadas. Além disso, o pisoteio do solo ocasiona a compactação, obstruindo a infiltração e facilitando o escoamento superficial (VasconceloS Sobrinho, 1971 apud Rodrigues, 1986, p. 28).

A agricultura é desenvolvida, majoritariamente, em pequenas propriedades com baixo nível tecnológico e dependente das variações climáticas nas duas áreas pesquisadas. Em Gilbués há uma variedade menor de produtos conforme pode ser observado no quadro 2 :

Quadro 2: Produção agrícola de Gilbués e Cabrobó em 2013

\begin{tabular}{|l|l|l|}
\hline \multicolumn{1}{|c|}{$\begin{array}{c}\text { Tipos de } \\
\text { lavoura }\end{array}$} & \multicolumn{1}{c|}{ Lavoura Temporária } & \multicolumn{1}{c|}{ Lavoura Permanente } \\
\hline Gilbués & $\begin{array}{l}\text { algodão, arroz, fava, feijão, } \\
\text { mandioca, milho e soja }\end{array}$ & $\begin{array}{l}\text { banana, castanha-de-caju e } \\
\text { laranja }\end{array}$ \\
\hline Cabrobó & $\begin{array}{l}\text { arroz, batata doce, cebola, } \\
\text { melancia, tomate }\end{array}$ & $\begin{array}{l}\text { banana, coco-da-baía, goiaba, } \\
\text { laranja, mamão, manga e } \\
\text { maracujá }\end{array}$ \\
\hline
\end{tabular}

Fonte: IBGE, 2014.

De modo geral os solos de Gilbués são pouco apropriados para a agricultura, entretanto, com práticas corretivas de manejo de solo, como adubação e calagem, tornam-se extremamente produtivos. 
A expansão da fronteira agrícola no sul do estado do Piauí começou na década de 1980, no topo das chapadas, onde o terreno plano e a boa qualidade do solo, propiciaram o desenvolvimento da produção de soja. Com a retirada da vegetação natural e a exposição do solo durante boa parte do ano tem acelerado o processo de erosão superficial e, com o transporte das águas pluviais, os sedimentos são depositados no leito dos rios provocando assoreamento (figura 4).

Figura 4: Solo exposto em uma fazenda de soja no sul do estado do Piauí, Brasil.

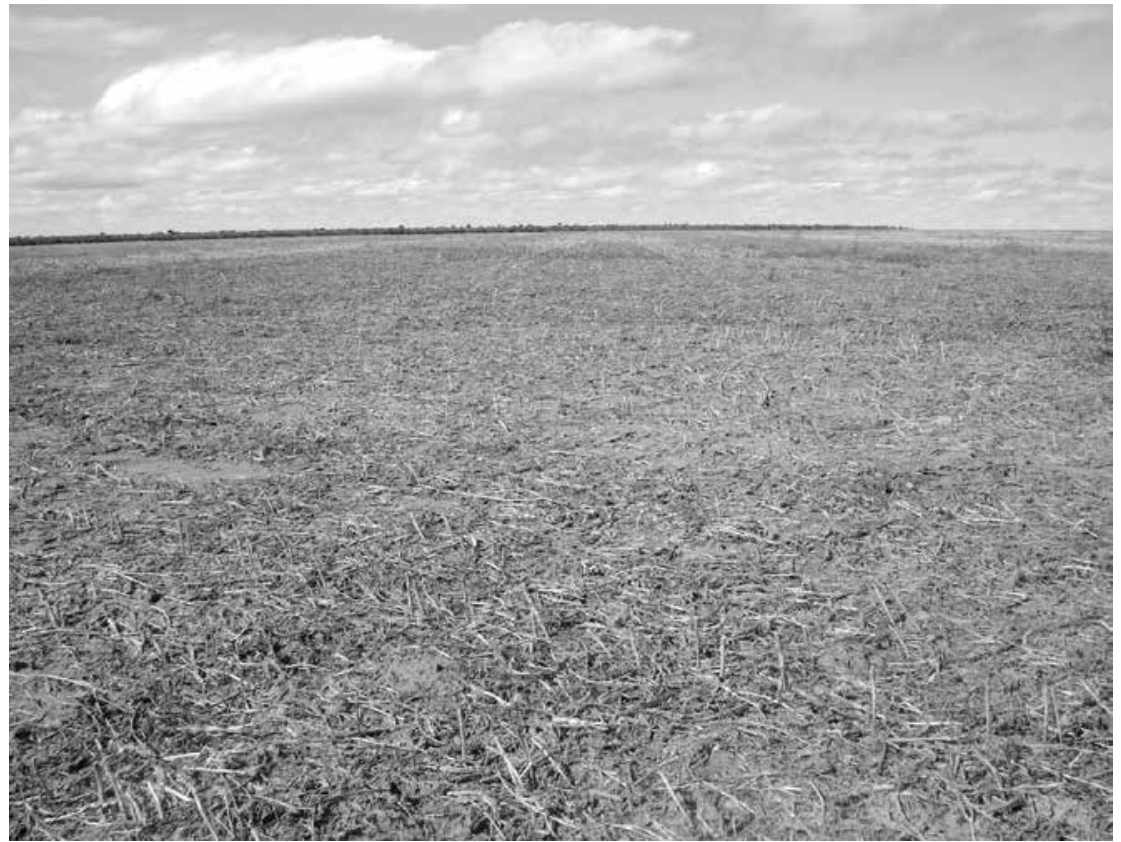

Fonte: Lopes, 2007.

Em Cabrobó a problemática agrícola está na produção irrigada, especialmente da cebola. A baixa permeabilidade do solo dificulta a drenagem e o alto teor de sais na água de irrigação acelera o processo de salinização (figura 5). O tipo de solo usado para irrigação influencia no efeito adverso onde ela é aplicada. Em solos permeáveis e profundos, como os de Gilbués, os riscos de salinização são menores. 
Laryssa Sheydder de O. Lopes, Rafael Celestino Soares. Desertification susceptibility of Gilbués (Piauí State) and Cabrobó (Pernambuco State) drylands, in northeastern Brazil.

DOI: http://dx.doi.org/10.15359/rgac.1-56.13

Figura 5: Produção agrícola irrigada na Ilha de Assunção em Cabrobó, Pernambuco, Brasil.

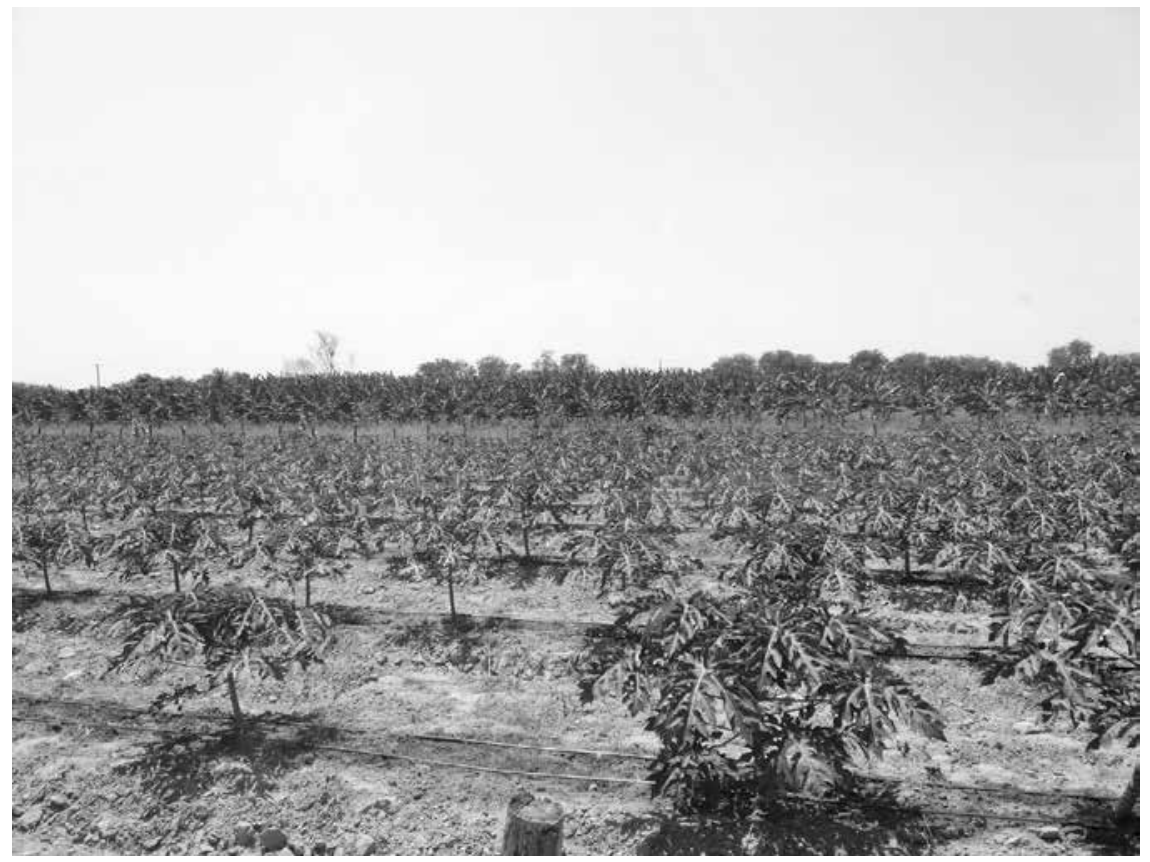

Fonte: Lopes, 2014

As temperaturas em subsuperfície são mais elevadas do que a camada superficial do solo, o que faz com que a água armazenada em profundidade migre para a superfície por capilaridade. Durante o dia a água evapora, liberado o sal que havia sido dissolvido. Por ser um processo diuturno, o sal se acumula ao ponto de, ao se associar com argilas, formar crostas que diminuem a porosidade/permeabilidade [...] (Soares, 2011, p. 56).

O fogo, tradicionalmente ligado à agricultura, é uma prática de manejo comum nas duas áreas pesquisadas e pode ser benéfico ou prejudicial, de acordo com a intensidade. As queimadas em grandes proporções podem prejudicar a fauna, destruir os microorganismos e impedir o rebrotamento da vegetação. Acontece que as queimadas são praticadas pelos agricultores em intervalos de tempo muito curtos, geralmente uma vez ao ano, quando elas deveriam ser feitas num espaço temporal maior, para que o solo se recupere (Lopes, 2011). 
Outro agravante em Gilbués foi a garimpagem artesanal de diamantes iniciada a partir da década de 1950. Esta atividade, apesar de ter dinamizado a economia local, ocorreu de forma predatória, sem nenhum controle. Toda a lavra era levada clandestinamente para estados do Sudeste e Cento-Oeste e a partir da década de 1970 a atividade entrou em declínio devido ao esgotamento das jazidas.

O grau de impacto da mineração em relação ao processo de desertificação foi pontual, no leitos dos rios e fora da área desertificada, concentrando-se no povoado Boqueirão do Garimpo, no município de Monte Alegre. Com a queda da atividade, as áreas antes exploradas pela mineração foram ocupadas com grandes projetos agrícolas com a utilização de práticas de queimadas e uso de mecanização pesada.

\section{Conclusões}

As áreas estudadas neste trabalho têm aspectos ambientais de solo, clima, e vegetação diferentes mas apresentam um histórico de uso e ocupação do solo em comum. Faz parte do cenário estas características ambientais, no entanto o manejo inadequado do solo pode vir a acelerar o processo natural de desertificação. A desertificação origina-se da pressão intensa das atividades humanas sobre ecossistemas frágeis, com fraco poder de regeneração.

As causas da degradação em Cabrobó estão atribuídas ao sobrepastoreio, desmatamento e principalmente à salinização do solo enquanto em Gilbués as causas estão ligadas com maior ênfase à natureza da estrutura geológica em que a área está assentada, contribuindo também a pecuária, o desmatamento e mesmo que pontualmente, a mineração.

Em suma, as consequências da desertificação resulta no empobrecimento da população local e declínio da qualidade ambiental, em processos migratórios intraregionais, perda de biodiversidade e de território. 
Laryssa Sheydder de O. Lopes, Rafael Celestino Soares. Desertification susceptibility of Gilbués (Piauí State) and Cabrobó (Pernambuco State) drylands, in northeastern Brazil.

DOI: http://dx.doi.org/10.15359/rgac.1-56.13

\section{Referências}

Ab'Saber, A. N. (2010). A problemática da desertificação e savanização no Brasil Tropical. In: Bartoreli. A. Obra Completa de Aziz Nacib Ab 'Saber. São Paulo: BECA.

Aquino, C. M. S., y Oliveira, J. G. B. de (2006). Suscetibilidade das terras secas do estado do Piauí à desertificação: avaliação a partir de índices. Mercator, 5(9) 49-60.

BRASIL. (1997). Comissão de Políticas de Desenvolvimento Sustentável e da Agenda 21 Nacional. Agenda 21. Brasil, 160p.

Instituto Brasileiro de Geografia e Estatística. (IBGE). (2014). Cidades. Disponível em: www.cidades.ibge.gov.br. Acesso em: novembro de 2014.

Instituto Brasileiro de Geografia e Estatística. (2010). Censo Demográfico. Disponível em: www.cidades.ibge.gov.br. Acesso em: dezembro de 2015.

Hare, F. K., Warren, A., Maizels, J. K., Kates, R. W., Johson, D. L., Haring, K. y Johson Garduño, M. A. (1992). Desertificação: causas e consequências. Lisboa: Fundação Calouste Gulbemkian.

Lopes, L.S.O., Santos, R. W. P. dos. y Miguel Filho, M. A. (2011). Núcleo de desertificação de Gilbués: causas e intervenções. Revista Geografia (Londrina), 20(2), 53-66.

Matallo, JR, H. (2001). Indicadores de desertificação: histórico e perspectivas. Brasília: UNESCO.

Melo, J. A. B. de, Lima, E. R. V. de y Pereira, R. A. (2008). Abordagem teórico-conceitual sobre riscos e perigos e sua manifestação no semiárido brasileiro através da desertificação. OKARA, 2(2), 164-176.

Perez-Marín, A. M., Cavalcanti, A. de M. B. y Medeiros, S. S. de, Tinôco, L. B. de M. y Salcedo, I. H. (2012). Núcleos de desertificação no semiárido brasileiro: ocorrência natural ou antrópica? Parcerias Estratégicas. Brasília,17(34), 87-106.

Pfaltzgraff, P. A. dos S. (2010). Geodiversidade do Piauí. Recife: CPRM. Rodrigues, V. (1986). Situação de desertificação no Estado do Piauí. In: SEMA. Seminário sobre desertificação no Nordeste: documento final. Brasília.

Sales, M. C. L. (2003). Degradação ambiental em Gilbués-Piauí. Mercator, 2(04) 115-125. 
Sampaio, E. V. S. B., Araújo, M. do. S. y Sampaio, Y. S. B. (2005). Impactos ambientais da agricultura no processo d desertificação no Nordeste do Brasil. Revista de Geografia. Recife, 22(1).

Santos, J. M. dos. (2011). Estratégias de convivência para a conservação dos recursos naturais e mitigação dos efeitos da desertificação no semiárido. In: LIMA, R. da. C. C. (org.) Desertificação e mudanças climáticas no semiárido brasileiro. Campina Grande: INSA-PB.

Silva, A. K. de. O.; y Silva, H. P. de B. (2015). O processo de desertificação e seus impactos sobre os recursos naturais e sociais no município de Cabrobó, Pernambuco, Brasil. Revista Eletrônica de Humanidades do Curso de Ciências Sociais da UNIFAP, 8(1), 203-215.

Soares, D. B., Mota Filho, F. de O. y Nóbrega, R. S. (2011). Sobre o processo de desertificação. Revista Brasileira de Geografia Física. Recife, 01, 174-188.

Suertegaray, D. M. A. (2000). Desertificação: recuperação e desenvolvimento sustentável. In: A. J. T; CUNHA, S. B. Geomorfologia e meio ambiente. 3 ed. Rio de Janeiro: Bertrand Brasil.

Vasconcelos sobrinho, J. (1971) Núcleos de desertificação no polígono das secas: nota prévia. Recife: SUDENE.

Vieira, R. M. S. P., Tomasella, J., Alvalá, R. C. S., Sestini, M. F., Affonso, A. G., Rodriguez, D. A., Barbosa, A. A., Cunha, A. P. M., Valles, G. F., Crepani, E., Oliveira, S. B. P., Souza, M. S. B. de., Calil, P. M., Carvalho, M. A. de., Valeriano, D. M., Campello, F. C. B. y Santana, M. O. (2015). Identifying areas susceptible to desertification in the Brazilian Northeast. Soid Eart, 6, p.347. 